\title{
MOSTRAR O MODERNO. VIVER O POSSÍVEL REPRESENTAÇÕES DE EDUCAÇÃO EM ROMANCES MODERNISTAS PAULISTASi
}

\author{
DISPLAY THE MODERN, LIVE THE POSSIBLE. \\ EDUCATION REPRESENTED IN SÃO PAULO MODERNIST LITERATURE
}
ENSEÑAR EL MODERNO, VIVIER LO POSIBLE. REPRESENTACIONES DE EDUCACIÓN EM ROMANCES MODERNISTAS 'PAULISTAS'

Vanessa Konopczyk Amaral Ribeiro ${ }^{1}$

\begin{abstract}
RESUMO
A pesquisa em andamento identifica como são representados os não escolarizados, os escolarizados e a escola, em obras consagradas da literatura paulista do período modernista, a fim de se compreender as relações sociais que são travadas a partir da representação que os autores fazem da docência e dos letrados quanto das pessoas não escolarizadas pela forma tradicional, procurando identificar a forma como se costuram essas relações, muitas vezes permeadas de preconceitos, vez que são representações tecidas por pessoas de sucesso escolar comprovado e posicionadas fora do campo educacional. As análises serão realizadas mediante leitura do conjunto documental escolhido, que se pauta a partir de três frentes: obras em prosa exclusivamente paulistas, de autores consagrados pela participação na Semana de Arte Moderna e sua filiação partidária. Após a leitura identificar-se-ão e extrair-se-ão os dados para sua comparação com os objetivos propostos, para fins de comprovação de indícios de rupturas e permanências de práticas sociais sobre os assuntos abordados. A partir de então será avaliado o cumprimento dos objetivos da pesquisa, a fim de encontrar a fundamentação e consistência necessárias para validar os vestígios percebidos nas obras analisadas.
\end{abstract}

PALAVRAS-CHAVE: Representação Social. Escolaridade. Escolarização.

\begin{abstract}
The ongoing research identifies how the educated, the unschooled and the school are represented in consecrated works of São Paulo literature of the modernist period, in order to understand the social relations established from the representation made by the authors of teaching, the educated as well as of the noneducated in the traditional way, looking forward to identify how are formed these relations often permeated by prejudice, since these representations are made by academically successful people out of the education field. The analysis will be performed by reading the set of documents chosen, which is guided from three fronts: prose works exclusively from São Paulo, works from authors consecrated by their participation in the Week of Modern Art and works by party affiliation. After reading one will identify and extract the data to compare with the proposed goals, to find evidences of ruptures and permanence of social practices of the subjects covered. From this analysis the fulfillment of the objectives will be evaluated in order to seek foundation and consistency to validate the traces perceived in the works.
\end{abstract}

KEYWORDS: Social representation. Education. Schooling.

\footnotetext{
${ }^{1}$ Doutoranda em Educação - Universidade Estadual de Campinas (UNICAMP) - Campinas, SP - Brasil. E-mail: konopczyk@hotmail.com

Submetido em: 12/06/2016 - Aceito em: 17/10/2016
}

(C) ETD-Educação Temática Digital Campinas, SP $\quad$ v.19 n.3 $\quad$ p. $864-881 \quad$ jul./set. 2017




\section{RESUMEN}

La investigación en curso identifica como los no escolarizados, los escolarizados y la enseñanza aparecen representados en las obras más consagradas del periodo modernista de la literatura de São Paulo con el fin de entender las relaciones sociales establecidas a partir de la representación que sus autores hacen tanto de los docentes, como de la docencia y de las personas que no están capacitadas por la vía tradicional, identificando así la forma en la que se construyen dichas relaciones, a menudo afectadas por prejuicios debido a que son tejidas por personas de comprobado éxito académico y posicionadas fuera del ámbito de la educación. El análisis se llevará a cabo mediante la lectura de la documentación seleccionada y se guiará por tres vertientes: las afiliaciones políticas de los autores, su participación en la Semana de Arte Moderno y de obras en prosa exclusivamente procedentes de la literatura de São Paulo. Tras la lectura, se identificarán y extraerán los datos necesarios para su comparación con los objetivos propuestos y para la comprobación de la evidencia de ruptura o permanencia de estas prácticas sociales en relación con los temas tratados. A partir de entonces, se evaluará el cumplimiento de los objetivos de la investigación con el fin de fundamentar cualquier resquicio hallado en las obras analizadas.

PALABRAS CLAVE: La representación social. Educación. La escolarización.

\section{INTRODUÇÃO}

Este texto traz as primeiras impressões a respeito do conjunto de leituras do período modernista paulista, proposto para a pesquisa de doutorado em andamento, que visa identificar como os escritores, oriundos de camadas burguesas ou que com ela mantinham relações, produziram um discurso de representação de escola e da docência operando de um lugar descolado do campo educacional. As intenções que motivaram a pesquisa em obras de literatura circunscrevem-se em uma trajetória que agrega gosto pessoal e um olhar que entende relações indissociáveis entre a história e as obras literárias, aqui referenciadas como fonte.

A literatura possibilita ao pesquisador de História lidar com as representações sociais, segundo o conceito de Roger Chartier (1991), porque o pensamento não se descola das práticas, sendo impossível separar o autor de obras ficcionais do autor intelectual que pensava o mundo na ocasião, visto que se confundem. Alguns trechos das obras corroboram a fala de Chartier, na medida em que os autores constroem perfis de professores, representam situações sociais e econômicas que enfrentam, revelando uma forma de olhar para esse grupo.

Por outro lado, as pistas a serem seguidas na busca por essas representações devem considerar que se se trata de representações de estratos sociais sob o olhar de outro estrato, privilegiado socialmente e detentor do capital intelectual necessário para a

(C) ETD-Educação Temática Digital $\quad$ Campinas, SP $\quad$ v.19 $\quad$ n.3 $\quad$ p.864-881 jul./set. 2017


construção da representação. Trata-se de pessoas com sucesso escolar confirmado, autores valorizados na construção do discurso social, escrevendo sobre a escola.

Neste sentido, as obras escolhidas para análise representam e são representantes das práticas de um grupo intelectual, as quais se buscam identificar e entender como se mesclam às representações educacionais da época, circunscrita entre as décadas de 1920 e 1940. As obras analisadas, publicadas nesse período ou que se referem a ele, traduzem a representação como afirma Carlo Ginzburg (2001), fazendo as vezes da realidade representada, sugerindo a presença e também a realidade ausente daquilo que pretende representar.

A perspectiva teórica que orienta essa pesquisa parte das reflexões de análise de Pierre Bourdieu (2007), cujo conceito de capital possibilita olhar para as representações de escola feitas pelos intelectuais modernistas sob o viés da estratégia de demarcação dos espaços de poder de uma elite que detinha o lastro possível para garantir a continuidade de seus privilégios. Para o autor, o capital cultural agrega-se ao capital social e econômico, propiciando que a estrutura social se perpetue. A reprodução da estrutura de distribuição do capital cultural se dá na relação entre as estratégias das famílias, que tendem a perpetuar seu ser social com todos seus poderes e privilégios, sendo a base das estratégias de reprodução, que se utiliza de dispositivos econômicos, educativos e outros, a fim de garantir privilégios.

Essa consideração é fundamental para a discussão deste texto e para o fechamento da fundamentação teórica sob a perspectiva de Sérgio Miceli (2001), cujo trabalho de análise, desenvolvido em Intelectuais à brasileira, retoma os conceitos de capital cultural para situar os intelectuais escritores. Segundo Miceli, os escritores modernistas de São Paulo estiveram invariavelmente envolvidos com as camadas mais privilegiadas da sociedade paulista, sendo que a maior parte deles tem origem burguesa, o que impulsionou seu trânsito pelos círculos socioculturais do mecenato paulistano da época, que, como pares, trataram de financiar seus intentos.

Pensando e agindo como baluartes da intelectualidade nacional, os modernistas se relacionaram com a cultura e a educação, mantendo estreitos laços com a política, flertando com cargos públicos e demarcando espaços de poder, de acordo com Miceli (2001), que demonstra como esses intelectuais corresponderam às expectativas ditadas pelos interesses das classes dirigentes. Dessa forma, como objetivo de análise, busca-se compreender como pessoas situadas fora do campo educacional e sem preocupações pessoais de escolarização, representavam a escola como dispositivo de ascensão.
(C) ETD- Educação Temática Digital
Campinas, SP
v.19
n.3
p. $864-881$
jul./set. 2017 
Pelas razões expostas, entende-se que as contribuições teóricas de Bourdieu e Miceli se revelam pertinentes a essa análise, que, para além das representações sobre a escola e a docência, identifica nuances de poder travadas pelos modernistas na manutenção de um status favorável aos privilégios inerentes à classe que pertenciam, observando que suas obras foram editadas por pares.

\section{A LITERATURA E SEUS SUJEITOS}

O autor francês Roger Chartier (1999) afirma que os livros são objetos que comandam a imposição de um sentido ao texto que carregam, podendo ser investidos de usos e intenções, notadamente de senso pragmático, afirmando também que os escritores são dependentes de regras que definem sua condição de submissão ao mercado editorial. Pode-se fortalecer a análise das obras dos autores modernistas sob esse olhar intencional, sobretudo quando se problematiza com seus lugares de produção intelectual e são identificados sua realidade, seu cotidiano e suas preocupações, presentes nas obras.

No entanto, é preciso reforçar que Chartier remete a uma realidade francesa e particular do século XVIII, elemento de sua obra. Nos termos em que coloca, os escritores seriam dependentes dos livreiros e editores, jamais conseguindo encerrar suas intenções nas próprias obras, não alcançando nem os operários da impressão nem os que se apropriam da leitura. Segundo o autor, isso se daria por conta das determinações que organizam o espaço social da produção literária, que delimitam as categorias e experiências próprias das matrizes da escrita.

Entende-se que o autor trata de uma situação diversa da proposta deste trabalho, pois, ao contrário da realidade apresentada por Chartier, o que se verifica entre os modernistas de São Paulo são formas de corroborar o poder que se estabelece horizontalmente, visto que a relação que se sugere entre os autores modernistas e os editores obedece mais a uma lógica de classe e espaço social, a qual não indica submissões, repressões ou dependências mercadológicas, já que se trata de pares.

Para compreender essa relação de igualdade, entende-se que a leitura de Bourdieu (2007) auxilia no alcance dessas relações horizontais e complexas que se mesclam ao campo da produção cultural, que Bourdieu afirma propor aos envolvidos o que ele denomina de espaço de possíveis, algo que faz com que os produtores de uma época sejam ao mesmo tempo situados, datados e relativamente autônomos em relação às determinações do ambiente econômico e social. Em um espaço de possíveis, os escritores estariam situados em relação aos editores, não havendo características de sujeição.
(C) ETD- Educação Temática Digital
Campinas, SP
v.19
n.3
p. $864-881$
jul./set. 2017 
Neste caso específico, esse posicionamento indica a necessidade de entender que a dinâmica da produção editorial paulista se baseou na tomada de posição por parte de autores e editores, que orientou sua produção mediante um universo de referências de classe e marcas intelectuais que correspondem a esse espaço, em detrimento de escolhas submetidas a condições econômicas, subvenções, ganhos ou ao provável sucesso editorial. Ou seja, no espaço de possíveis ocorre uma relação circular entre editores e autores, na qual se operam dinâmicas de uns para os outros, sem que existam meras determinações econômicas e causais para definir tomadas de posição.

Bourdieu (2007) ainda afirma que a reflexão sobre a literatura obedece a essa lógica. As escolhas do espaço de possíveis estabelecem a existência de uma relação entre as tomadas de posição e as posições ocupadas no campo social, indicando relações entre o que se produz, opiniões e valores defendidos e o lugar ocupado no campo. Por pertencerem à mesma classe social e possuírem semelhante filiação cultural, editores e autores aqui não operam uma relação de força, mas uma relação de possíveis.

O trabalho de análise em fontes literárias necessariamente requer atenção quanto aos vínculos adjacentes que amarram práticas sociais disseminadas, segundo Antonio Candido (1965), em Literatura e Sociedade. Os autores modernistas escreveram com elementos de seu tempo e expressaram uma representação sobre a escola em suas obras que os situa nesse lugar.

A análise histórica a partir de fontes literárias deve privilegiar pequenos detalhes de fragmentos presentes nas obras, que, escritas para ser arte, e não documentos oficiais, invariavelmente escapam aos tradicionais critérios de análise justamente por não se apresentarem como documentos prontos, cujas temporalidades são bastante definidas. Por meio da análise da literatura proposta é possível apreender, entre outras situações, a forma de representação dos intelectuais citados, auxiliando na construção de uma identidade de grupo a partir de São Paulo, ainda que seja de caráter autoritário e marcado pela distinção.

Para tanto, torna-se necessário demonstrar por quais trilhas deverá seguir essa pesquisa, a fim de buscar o objetivo citado. A primeira trilha encerra a análise em obras em prosa, exclusivamente, de autores modernistas paulistas, que, em sua maioria, pertenciam às classes sociais mais privilegiadas e naturalmente mantinham relações com o poder. Mesmo entre os intelectuais que não tinham origem abastada, há o elemento comum da proximidade de suas famílias com a intelectualidade e com a política dominante. Como se trata de um grande espectro de obras, é importante destacar que, após o levantamento e a
(C) ETD- Educação Temática Digital
Campinas, SP
v.19
n.3
p. $864-881$
jul./set. 2017 
leitura de todas, apenas algumas serão capazes de responder às interrogações propostas na pesquisa.

Uma segunda trilha propõe fechar a análise nos autores modernistas que possuíam alguma filiação política. A questão partidária é particularmente importante porque destaca como a intelectualidade paulista se reorganizou politicamente, a fim de se preservarem à frente de instituições de poder e, mais ainda, na manutenção de seus privilégios, os quais, segundo Miceli (2001), estavam em decadência, ameaçados principalmente após 1930. 0 projeto de expansão da elite decadente impulsionou a criação de novas frentes partidárias, que, na verdade, tendiam à acomodação de forças da própria elite paulista, até então identificada e representada pelo Partido Republicano Paulista, o PRP.

Essa consideração permite apreender como a exaltação de São Paulo como símbolo de status cultural alcançou tamanho vulto e alcance, uma vez que só era compreendido pelos próprios pares. A elite paulista, cada vez mais acuada politicamente, exalta sua provável posição de superioridade cultural, por meio da literatura modernista, e constrói formas de representação para manter privilégios de classe. Trata-se de um modelo de difusão cultural que, baseado em propostas vanguardistas, de ruptura com os padrões estéticos tal como nos moldes europeus, promoveria um verniz à velha instituição oligárquica decadente, capitaneada pelo Partido Republicano Paulista, o PRP.

Para Sérgio Miceli (2001), apesar do sucesso dos autores modernistas por conta de suas inovações na estética, as rupturas e insatisfações dentro da própria oligarquia fatiaram as intenções de poder dessa classe, que, empobrecida, promoveu dissidências políticas que tornaram ainda mais visível a fragilidade do modelo partidário paulista. O Partido Democrático, criado nessa conjuntura, em 1926, reuniu parte da dissidência perrepista.

Os escritores vinculados ao PRP colocaram suas obras a serviço de uma ideologia "nacionalista", da qual poderiam se utilizar os grupos dirigentes. Nesse caso, acabaram cindindo à direita ou esquerda literárias por causa de posições divergentes quanto ao grau e às modalidades de engajamento dos intelectuais com o trabalho político. Neste grupo estão Oswald de Andrade, perrepista e depois membro do Partido Comunista, Menotti del Picchia, Cassiano Ricardo, Paulo Duarte, Alcântara Machado, Cândido Mota Filho e Plínio Salgado, que num primeiro momento pertenceu ao PRP e depois foi o personagem central do Partido Integralista.

Para Miceli (2001), o grupo dos intelectuais "democráticos", composto por Mário de Andrade e Guilherme de Almeida, se empenhou em não deixar que suas tomadas de
(C) ETD-Educação Temática Digital
Campinas, SP
v.19 $\quad$ n.3
p. $864-881$
jul./set. 2017 
posição no terreno político-partidário pudessem comprometer o conteúdo de sua produção literária e estética. Buscava resguardar a problemática de sua produção intelectual dentro das conveniências impostas pelas lutas das quais participava. O Partido Democrático pretendia a moralização eleitoral, a modernização e a reforma do sistema de ensino. Essa mentalidade, aliada às insatisfações dentro do PRP, ajudou na conquista da nova geração oligárquica, mas, por conta de sua formação e origem, manteve ausente a representação política da classe operária.

A última trilha reservará uma categoria de relatos autobiográficos, a fim de se elaborar um quadro comparativo com a ficção. Essas categorizações tornaram-se necessárias para fechar a análise do período, bastante extenso em termos de produção intelectual, já que seus autores escreveram prosa, poesia, ensaios, críticas literárias, traduções e textos técnicos na área jurídica.

A escolha dessas categorias foi desenhada a partir do trabalho de Sérgio Miceli, que, em Intelectuais à Brasileira (2001), reuniu e estudou os autores modernistas de São Paulo a partir de sua origem, curso superior, carreira e tipo de produção, entre outros. A partir do estudo desenvolvido por Miceli recorreu-se ao levantamento das obras dos autores. Pela classificação proposta por Wilson Martins (2002), que indica os autores fundamentais do modernismo paulista, estabelecemos o conjunto de fontes que será analisado.

\section{OS AUTORES E SUAS OBRAS}

Diante dos critérios estabelecidos, serão analisadas as obras de Oswald de Andrade (Os Condenados, Marco Zero I e Marco Zero II, Memórias Sentimentais de João Miramar, Serafim Ponte Grande e Um Homem Sem Profissão, no qual narra suas memórias), de Mário de Andrade (Contos Novos, Primeiro Andar, Macunaíma, Os Contos de Belazarte, Os Filhos da Candinha e Amar, Verbo Intransitivo) e os romances de Menotti del Picchia (A filha do Inca, A Tormenta, A Mulher Que Pecou, Laís, Dente de Ouro, Salomé, A Tragédia de Zilda, Cummunka, Kalum, O Homem e a Morte: Tragédia Cerebral além do autobiográfico A Longa Viagem). Serão realizadas ainda análise dos seis romances escritos por Plínio Salgado (Trepandé, O Eestrangeiro, O Cavaleiro de Itararé, O Esperado, A Voz do Oeste e O Dono do Mundo), as obras de Antônio Castilho de Alcântara Machado (Mana Maria, Laranja da China, Brás, Bexiga e Barra Funda), além das prosas A Casa, Natalika e Baile de Formatura, de Guilherme de Almeida.

As obras escolhidas para essa análise preliminar contemplam Dente de Ouro (1923) e Salomé (1940), de Menotti del Picchia, além de Os Filhos da Candinha, que contempla vários (C) ETD-Educação Temática Digital $\quad$ Campinas, SP $\quad$ v.19 $\quad$ n.3 $\quad$ p.864-881 jul./set. 2017 
contos publicados entre as décadas de 1920 e 1930, e Os Contos de Belazarte, reunião de contos publicados inicialmente na década de 1920, de Mário de Andrade, talvez o mais emblemático dos modernistas, intelectual ligado ao Partido Democrático, além das obras de Oswald de Andrade, Os Condenados, Marco Zero I e Marco Zero II, e o autobiográfico Um Homem Sem Profissão. Oswald também teve atuação política. Em um primeiro momento também pertenceu ao velho PRP e depois, já mais velho, atuou no Partido Comunista do Brasil.

Percebe-se nas obras a preocupação dos intelectuais com o Brasil, e com São Paulo em particular, e fragmentos que indicam representações sobre a escola e a docência. É interessante notar a pouca ou mesmo ausente representação de escola, escolaridade e cotidiano dos pouco escolarizados. Até o momento, o material investigado é bastante revelador de uma exclusão, e essa ausência pode indicar tanto o lugar social de quem vê a escola, no caso os autores, posicionados fora do campo, como pode indicar o lugar que eles, autores consagrados e herdeiros da elite, oferecem à importância da escola e da escolarização como pilares de ascensão social, visto que já o possuíam.

O propulsor da mudança na literatura reside nas lutas que visam conservar ou transformar a relação de forças instituída no campo de produção e têm, evidentemente, o efeito de conservar ou de transformar a estrutura do campo das formas de que são instrumentos e alvos nessas lutas. Muitas vezes, apesar da modernidade que carregam, os autores evidenciam representações que soam conservadoras, mas, no entanto, são características de demarcação de espaços de poder.

Bourdieu (2007) explica esse tipo de relação por meio do conceito de campo do poder, o espaço das relações de força entre os diferentes tipos de capital ou, mais precisamente, entre os agentes providos de um tipo de capital específico que favorece a dominação de um grupo. As forças se intensificam sempre que o valor relativo dos diferentes tipos de capital é posto em questão, especialmente quando os equilíbrios estabelecidos no interior do campo, entre instâncias encarregadas da reprodução do campo do poder, são ameaçados.

Nessa perspectiva, encontram-se os intelectuais modernistas, que, oriundos de uma elite economicamente falida, ainda possuíam fôlego e capital para permanecerem atrelados e atuantes nos espaços de poder que Ihes garantiram visibilidade e publicações, engenhosamente combinando o capital cultural que detinham com a estrutura do espaço social, o que Bourdieu (2007) define como modo de reprodução. Nessa perspectiva de análise, é fundamental reforçar que as ausências percebidas também são reveladoras de
(C) ETD-Educação Temática Digital Campinas, SP
v.19 $\quad$ n.3
p. $864-881$
jul./set. 2017 
contradições e relações políticas e ajudam a identificar como se formam e se sedimentam as representações acerca dos grupos escolhidos.

Em algumas obras analisadas foi possível perceber indícios e formas de representação da escola, da docência, da educação dos sem escola, além de assuntos correntes na preocupação e no pensamento da intelectualidade da época. A análise integra temas que vão desde a representação de escolas primárias, secundárias, curso superior, até as formas de representação que passam pela educação sexual, da representação dos professores como eivados de missão redentora e moralizante, presentes nas próprias obras.

Neste caso particular, a análise da literatura modernista paulista está atrelada ao viés artístico e não político, embora se afirme que os anseios modernistas, suas ideias inovadoras e até mesmo transgressoras no campo estético somente se tornam possíveis porque encontraram ressonância, identificação e correspondência entre seus pares. Em suas obras, apesar de representarem a educação de fora do campo educacional, suas ideias encontram subsídio e se harmonizam com ideias em voga na época em que publicaram seus romances.

Quadro 1 - Personagens e representações de Educação, os tipos e estereótipos profissão docente.

\begin{tabular}{|c|c|c|c|}
\hline Autor & Romance & Editora & Data publicação \\
\hline Menotti del Picchia & Dente de Ouro & $\begin{array}{l}\text { Monteiro Lobato \& Cia } \\
\text { Editores }\end{array}$ & 1923 \\
\hline Menotti del Picchia & Salomé & $\begin{array}{l}\text { Empresa Gráfica Revista dos } \\
\text { Tribunais }\end{array}$ & 1940 \\
\hline Oswald de Andrade & Marco Zero I & Livraria José Olympio Editora & 1943 \\
\hline Oswald de Andrade & Marco Zero II & Livraria José Olympio Editora & 1945 \\
\hline Oswald de Andrade & Alma (Os Condenados) & Livraria do Globo & 1922 \\
\hline Oswald de Andrade & $\begin{array}{l}\text { A Estrêla de Absinto (Os } \\
\text { Condenados) }\end{array}$ & Livraria do Globo & 1927 \\
\hline Oswald de Andrade & A Escada (Os Condenados) & Livraria do Globo 1941 & 1934 \\
\hline Oswald de Andrade & Um Homem Sem Profissão & Livraria José Olympio Editora & 1954 \\
\hline Mário de Andrade & $\begin{array}{l}\text { Os Filhos da Candinha (O } \\
\text { grande cearense) }\end{array}$ & Martins & 1943 \\
\hline Mário de Andrade & $\begin{array}{l}\text { Os Filhos da Candinha } \\
\text { (O diabo) }\end{array}$ & Martins & 1943 \\
\hline Mário de Andrade & $\begin{array}{l}\text { Os Contos de Belazarte } \\
\text { (Menina de olho no fundo) }\end{array}$ & Piratininga & 1934 \\
\hline Mário de Andrade & $\begin{array}{l}\text { Os Contos de Belazarte } \\
\text { (Piá não sofre? Sofre.) }\end{array}$ & Piratininga & 1934 \\
\hline
\end{tabular}

(C) ETD-Educação Temática Digital $\quad$ Campinas, SP $\quad$ v.19 $\quad$ n.3 $\quad$ p.864-881 jul./set. 2017


Busca-se nesse conjunto de livros as representações de "doutor", além de representações da escola como regeneradora da moral, representações de higiene e indicações de trabalho infantil, além de pistas sobre a origem social dos professores primários. A fim de compreender os autores em seus momentos de produção das obras, fazse necessário indicar alguns detalhes de suas trajetórias intelectuais, conforme Jean François Sirinelli (2003), para quem o meio intelectual constitui-se um microcosmo onde os laços estabelecidos entre eles se encontram em torno de uma redação ou de um conselho editorial, o que torna muito difícil identificar como se dão as redes de sociabilidade entre eles. No entanto, para Sirinelli, as publicações subentendem graus de amizade, fidelidade e influência, constituindo-se ao mesmo tempo como espaço de adesão e sociabilidade.

O microcosmo dos autores fundamentais do modernismo, a despeito das filiações contrárias que depois assumiriam as vertentes do movimento, orientava-se por estrutura de pensamento comum, redes de publicações e amizades partilhadas, bem como trajetória intelectual que guarda semelhanças. Esse universo constituiu-se no período entre as duas guerras e ao mesmo tempo em que a cidade de São Paulo lutava por uma identidade própria, segundo Nicolau Sevcenko (1992). Crescendo desordenadamente, a cidade, através de seus intelectuais, buscou preencher seus vazios de modos diversos. Os autores fundamentais do modernismo, por mais paradoxal que possa ser, buscaram um eixo de solidez para operar diante de situações desconhecidas, sobretudo causadas pela instabilidade política que atingia os grandes do PRP, segundo Miceli (2001).

\section{DAS TRAJETÓRIAS DOS AUTORES E FRAGMENTOS DAS OBRAS}

Menotti del Picchia nasceu em São Paulo em 1892. Filho de um pequeno empreiteiro, poeta e artista, ainda jovem perdeu a mãe e teve, ao longo de sua vida escolar, forte presença da Igreja Católica, na figura de padres e bispos que o auxiliaram a concluir seus estudos, por causa da a situação do pai, quase sempre incerta, segundo o que o próprio Menotti afirma em sua autobiografia, A Longa Viagem. Miceli (2001) observa que Picchia se formou em Direito e estreou na literatura em 1917, quando já atuava em órgãos de imprensa do Partido Republicano Paulista. Dono de carreira vasta e diversificada, Menotti conseguiu alcançar certa estabilidade na vida política mesmo após a ascensão de Getúlio Vargas.

Verifica-se que nos dois romances indicados de Menotti del Picchia, a representação sobre educação quase não aparece, limitando-se a uma citação em Salomé apenas no momento da "ajuda" ou da "regeneração" necessária para uma família miserável que vivia da assistência caridosa do Padre Nazareno. A experiência pessoal de Menotti, sempre às

$$
\begin{array}{llllll}
\text { (C) ETD- Educação Temática Digital } & \text { Campinas, SP } & \text { v.19 } & \text { n.3 } & \text { p.864-881 } & \text { jul./set. } 2017
\end{array}
$$


voltas com padres e bispos e empreendendo grande esforço pessoal e educacional para transitar nas esferas mais elevadas, pode auxiliar na compreensão dessa exclusão, vez que, em suas memórias, se observa certo orgulho pela dura trajetória que afirma ter tido até a consagração como escritor. Menotti afirma ainda que o bispo de Pouso Alegre, D. João Batista Nery, foi um dos grandes responsáveis por sua formação cultural.

Salomé é construído como uma crônica de costumes da elite paulista, cuja protagonista, que dá nome ao romance, tinha hábitos considerados escandalosos, por ter vivido na Europa. A segunda parte do romance tem como cenário um ambiente rural. A ficção criada por Picchia mostra a igreja e a cidadezinha de riachos e cafezais, revelando costumes da gente mais pobre do local, mas não traz indícios muito significativos sobre uma escola ou uma professora. Na cidadezinha atuava o Padre Nazareno, responsável pela única referência escolar de todo o livro. O Padre ajudava uma família paupérrima, de negros, composta pela avó, que vivia com a filha e quatro netos, que o autor frisa ser um de cada pai. A casa, descrita como um pardieiro imundo, exalava um terrível cheiro de excrementos. As crianças eram doentes e uma delas, malformada por causa da sífilis. O Padre Nazareno conseguiu vaga na escola para o menino mais velho, injeções de remédio e camas para as crianças:

[...] Nazareno já pusera um pouco de ordem naquela esterqueira. A velha preta era religiosa e temia o diabo. E ele utilizava-se desse diabo para domar a velha. A filha, que arranjara um pai diferente para cada cria, respeitava o padre. Os fedelhos tinham agora cada qual sua cama. O maior fora posto na escola. A situação ia melhorando. Precisava, porém, de algumas caixas de injeções porque o mal dessa negrada era a sífilis. [...] (p. 187).

O Padre também surge como professor nas aulas de catecismo, que explicava com criatividade, como se fossem contos da Carochinha (p. 215), para prender a atenção dos pequenos, logo após realizar uma inspeção higiênica nas crianças. O Padre Nazareno representa no romance a figura que se preocupava com a moralização dos costumes, com a higiene e com a educação, visto que foi por meio de sua assistência que um dos meninos passou a frequentar a escola.

Em Dente de Ouro não foram encontradas representações de escola ou de educação, mas há a representação do "doutor", o jovem delegado filho de um fazendeiro de café que, falido, entregou sua fazenda aos credores e pediu auxílio a um amigo que intercedesse junto ao secretário de Justiça para que arranjasse uma colocação para o rapaz. O jovem, que vai trabalhar no interior, estranha os costumes da cidade e todos o tratam por "doutor".

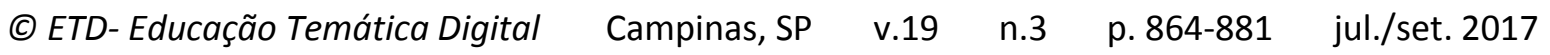


Novamente recorre-se a Miceli (2001) para compreender a trama trazida por Menotti del Picchia, filiado ao Partido Republicano Paulista. Miceli afirma que dentre a oligarquia paulista era prática comum que os filhos frequentassem a faculdade de Direito e depois as próprias relações estabelecidas dentro da elite engendrariam uma forma de inseri-los nos cargos públicos. No entanto, pouco a pouco os cobiçados postos tornaram-se cada vez mais escassos e reservados aos filhos da oligarquia que ainda conservava algum capital social ou político. Miceli afirma:

\footnotetext{
Até o início da década de 1920, tão logo tivessem cumprido os estágios de praxe como militantes da Liga Nacionalista ou das diversas facções acadêmicas em concorrência na Faculdade de Direito, os herdeiros das famílias dirigentes com veleidades de fazer carreira política viam-se obrigados a galgar todos os escalões do perrepismo. Os que porventura acabassem desistindo de tais pretensões tinham pelo menos a certeza de se saírem bem seja no plano profissional, seja em termos do apreço social a que faziam jus. (p. 93)
}

José Oswald de Souza Andrade nasceu em 1890, em São Paulo. Ao contrário de Menotti del Picchia, possuía origem abastada e uma rede de relações sociais e familiares que possibilitaram a manutenção de seu status quo ainda que não tivesse sido um aluno brilhante, como afirma na obra autobiográfica Um Homem Sem Profissão. Estreou no jornalismo em 1909, como crítico teatral, e em pouco tempo tornou-se conhecido e prestigiado no meio. Simultaneamente cursava Direito, como Miceli (2001) afirma ter sido o caminho quase natural para os filhos da elite. Em 1912 viajou para a Europa e só retomou o curso em 1916, por conta de uma promessa feita à mãe, já falecida. No mesmo ano estreou na literatura.

As obras de Oswald selecionadas aqui oferecem muitas referências sobre escola e docência, como representações patrióticas e indicação de origem social dos professores, como se observa em Marco Zero I e Marco Zero II, além de trazer memórias das escolas onde o autor estudou, na autobiografia Um Homem Sem Profissão.

Em outras representações importantes, como a da cultura erudita que envolve o professor alemão, além da representação de professores como eivados de significações sociais e idealizados, como se observa em Os Condenados - Alma, é clara a crítica tecida por Oswald de Andrade ao referir-se aos homens socialmente respeitáveis que frequentavam o rendez vouz onde Alma se prostituía, como se lê a seguir: 
[...] Tinha assistido, na sua crucificação, ao desfile em pelo de todos os exemplares. Diante dela, haviam-se desabotoado, numa confissão de torpezas, professores da cidade, chefes de confrarias, zeladores de hospitais, grandes nomes, representativos da moral citadina, da educação, da finança e da família. (p. 61)

Alma engravidou e teve um filho. Essa criança era alfabetizada em casa, o que sugere uma possível preocupação com a escolarização do menino. A moça deixou a casa de prostituição e contava com o auxílio de uma aia alemã para educar a criança: "Ensinaram-no a ler num grande livro de figuras: A-za, E-ma, I-Iha, Ô-vo, U-va." (p. 78).

A segunda parte da trilogia, A Estrela de Absinto, tem algumas passagens muito semelhantes às memórias do autor publicadas em Um Homem Sem Profissão, e a terceira, $A$ Escada, nada indica sobre o que está sendo buscado.

O livro de memórias Um Homem Sem Profissão é um relato autobiográfico. Oswald traz vários tipos de professores, desde as professoras primárias D. Orminda da Fonseca e D. Isabel Ribeiro, a quem lembra como "excelentes mestras", ao professor "Seu" Carvalho, "ateu danado". Oswald também recorda o edifício escolar "limpo, branco, higienizado", do ambiente do Caetano de Campos, os outros colégios por onde passou, como o Ginásio de São Bento e o Ginásio de Nossa Senhora do Carmo, dos irmãos maristas, que diz não ter suportado o ambiente nem aprendido muita coisa, guardando como sua melhor lembrança o café com leite servido no refeitório do colégio, após a comunhão. Oswald cita D. Matilde, a professora particular com quem estudou após sair do Marista, o professor de música, os colegas; relembra a severidade e a delicadeza de alguns antigos mestres; enfim, as memórias de sua vida escolar trazem representações do que era importante e adequado à sua classe social e merecem uma categorização à parte na pesquisa em andamento.

Em Marco Zero I e Marco Zero II, Oswald indica tipos de professores. Há a representação da professora primária de origem humilde e sofrida que, tendo obtido auxílio, conseguiu tornar-se professora, identificada na trajetória de Eufrásia Beato, e a representação da diretora implacável e rígida, na forma que ele dá a Anastácia Pupper.

A primeira, moça jovem e pobre, vivia em uma fazenda. A oportunidade de estudar em um colégio de São Paulo para se tornar professora foi dada pela dona da fazenda. Eufrásia Beato foi levada para São Paulo, onde aprendeu a tomar banho e escovar os dentes. Deslumbrou-se ao se tornar professora por acreditar que alfabetizaria o Brasil. No entanto, ciente das responsabilidades de sua nova função no Grupo Escolar, fumava escondido em seu quartinho para escapar da censura imposta pelos inspetores pelo vício.

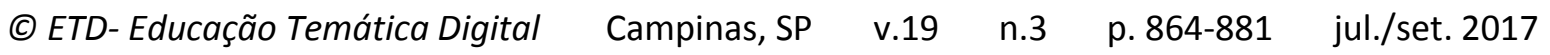


Eufrásia Beato ensinava o patriotismo paulista para as crianças do Grupo Escolar de Bartira. Descrita por Oswald como entusiasta da Revolução de 1932, suas lições sempre tinham bastante relevância de nacionalidade e patriotismo brasileiro e paulista, sobretudo. Oswald indica, de forma velada, que a professora Eufrásia Beato prestava alguns serviços em uma casa de rendez vouz, mesmo sendo professora do Grupo Escolar.

A partir de Eufrásia surge a representação do menino Idalício, um aluno que faltava muito às aulas. Diante das indagações da professora, a criança sempre respondia que precisava auxiliar a avó a fazer farinha. No entanto, Oswald explica que o menino faltava à escola por não ter roupas, descrevendo o cotidiano duro e sem perspectivas de Eufrásia, de forma que acabou abandonando a profissão. Após uma moléstia, Eufrásia não voltou ao Grupo.

Na segunda parte de Marco Zero, Chão, Eufrásia Beato vai para o Rio de Janeiro em busca de melhor sorte e acaba conhecendo um homem, a quem pede um apartamento mobiliado. Eufrásia abandonou a carreira docente por causa da doença e depois não quis voltar, preferindo ser mantida por um homem. Essa representação surge também no caso da diretora, Anastácia Pupper, que se valeu do amante para abandonar a carreira.

Oswald descreve Anastácia Pupper, a diretora do Grupo Escolar de Bartira, de forma bem diversa de Eufrásia, que era frágil e delicada. A diretora, ao contrário, é representada como uma mulher enérgica, exigente e gorda, que usava os cabelos oxigenados e tinha o nariz de bico. Anastácia Pupper afirmava que o professorado primário era uma tropa de choque da nacionalidade e pedia aos professores que fizessem uma chamada patriótica, que indicasse a origem de cada aluno. Apesar de sua aparente rudeza, a diretora se preocupava com os alunos que, assim como o menino Idalício, andavam até três quilômetros a pé para chegar à escola, sem comer nada, dizendo que isso lhe cortava o coração.

Anastácia Pupper era amante do cunhado, Idílio Moscovão, que pediu sua remoção para São Paulo ao Conde Alberto de Melo. Em São Paulo, a diretora trocou de amante e passou a se relacionar com o Conde, a quem pediu uma oportunidade fora do magistério. $O$ Conde fez dela deputada:

Pensava no novo amante. Que chance! [...] Daí, daquela manhã em que saíra desesperada de casa para pedir um emprego fora do magistério, viera a transformação de sua vida. Era deputada, feita pelo conde. (p.134)

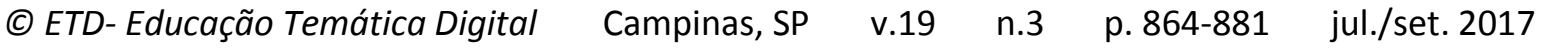


O único homem criado por Oswald de Andrade em Marco Zero é o professor Barnabé, que dava aulas de ginástica no Grupo Escolar de Bartira. Representado de forma completamente diferente das personagens femininas, Barnabé é tido por pessoa de pouca iniciativa e personalidade admirativa. Idealista, o professor Barnabé morreu durante a revolução paulista, a qual estava engajado.

Mário Raul de Moraes Andrade nasceu em 1893, na capital paulista. Considerado o mais emblemático dos modernistas de São Paulo, seus tipos de professores, representados nos contos indicados, são mais sutis em comparação aos tipos criados por Oswald, no que se refere à escola ou à escolarização.

A representação de Delmiro Gouvêia como grande disciplinador, na crônica $O$ Grande Cearense, de 1928, fala sobre um homem rude e batalhador que saiu do Pará para se empregar em Pernambuco, ainda criança, e teria conservado um grande caráter, a despeito do que acontecia no Brasil. Apesar de não se tratar de um professor, Mário indica práticas pedagógicas atribuídas a Delmiro Gouvêia:

\footnotetext{
Era um gênio da disciplina. [...] Si um menino falhava a aula, Delmiro mandava chamar o pai pra saber o porquê. Chegou a despedir os pais que roubavam um dia de estudo aos filhos, por causa de algum servicinho. Às vezes, com os meninos mandriões, reunia cinco, seis, e mandava um negrão chegar africanamente a palmatória na bunda dos tais. (p. 42)
}

Outras categorias que se podem identificar indicam a representação dos médicos como dotados de muito poder, como Mário de Andrade faz sugerir no conto O Diabo; a representação da aluna que, jovem e bonita, se aproveita dessa condição para flertar com os professores sem precisar estudar, como a menina Dolores, do conto Menina de Olho no Fundo; e o tipo de vestimenta usado pelas normalistas Margot e Nininha, que surge no conto Piá Não Sofre? Sofre.

É importante destacar que Mário de Andrade foi o único dos modernistas paulistas que não frequentou a Faculdade de Direito. Relegado à contabilidade, que não completou, e ao Conservatório Dramático e Musical, foi autodidata e assumiu a liderança do movimento modernista por meio de seu talento. Apesar de engajado no Partido Democrático, o que lhe garantiu alguns cargos, não conseguiu iniciar uma carreira política, como os demais autores. 


\section{CONSIDERAÇÕES FINAIS}

Após a leitura e a análise dos tipos e estereótipos que representam professores, doutores, pessoas escolarizadas ou sem escola, pode-se verificar o que ficou construído socialmente em termos de práticas culturais das elites em relação aos mais pobres. As representações indicadas pelos autores citados dão conta de imagens de professores como moralizadores, patrióticos, responsáveis por garantir disciplina, higiene e ordem, algo bem típico das décadas em que foram escritos ou do tempo a que se referem, entre as décadas de 1920 e 1940.

Simultaneamente, observam-se formas de representação que recriminam comportamentos não aceitos como moralizantes, como no caso dos professores que frequentavam casas de prostituição. Os autores, sobretudo Oswald de Andrade, indicam representações de doçura da professora primária, diferentemente da severidade indicada na representação da diretora do Grupo Escolar, descrita até de forma mais masculinizada.

Entendemos que toda forma de representar o outro vem atrelada a uma construção que perpassa o olhar de um grupo socialmente dominante. No caso de nossos intelectuais, a elite da literatura paulista, que desenvolveram carreira intelectual e política nos principais espaços de poder da época, inclusive nos partidos dominantes, como o Partido Republicano Paulista e suas dissidências, como o Partido Democrático, observamos que seus textos, bastante reveladores de suas práticas, são social e culturalmente definidos como parte de suas experiências de mundo, tanto exprimindo como construindo uma realidade social.

Suas obras, imprescindíveis para estabelecer conexões possíveis entre a intelectualidade paulista e o público em geral, representam sua filiação. Como afirma Bourdieu (2007), a instituição escolar demarca fronteiras semelhantes àquelas que separavam a nobreza da pequena nobreza, e esta dos simples plebeus. No caso dos intelectuais modernistas, sua escolaridade e sua rede de relações operaram como distinção de capital cultural herdado, garantindo a blindagem necessária para tratarem da representação de educação ainda que não tenham tido origem social elevada, como Menotti del Picchia, ou não tenham passado pela Faculdade de Direito, caso de Mário de Andrade.

Escrevendo para seus pares e operando com seu capital social que os fortaleceu em um conjunto de relações mobilizado a partir de interesses que tiveram como desdobramento o desenvolvimento de suas carreiras públicas, os autores modernistas não desenvolveram compromisso com a quebra de padrões políticos ou econômicos, tendo sua

$\begin{array}{llllll}\text { (C) ETD-Educação Temática Digital } & \text { Campinas, SP } & \text { v.19 } & \text { n.3 } & \text { p.864-881 } & \text { jul./set. } 2017\end{array}$ 
vanguarda amarrada às questões estéticas que vinham à baila expor insatisfações inerentes a uma classe social que, ao perceber-se encolhendo, adotou estratégias de continuidade e manutenção de seus espaços de poder através do mecenato, entre outras formas.

Dessa forma, acredita-se que os vestígios indicados até o momento permitem insistir na ideia de procurar nos romances modernistas uma representação de educação construída pela elite intelectual, que não promoveu rupturas com o antigo viés conservador dos valores sociais e tradicionais quanto à educação, mas, ao menos para a intelectualidade paulista, a modernidade se constituiu de uma resposta da oligarquia à sua crescente perda de espaços de atuação. Nesse caso, entende-se que por meio das artes, e da literatura em particular, a elite pudesse condensar suas práticas de ditar regras e condutas que estavam em maior ou menor grau, descoladas da realidade das pessoas comuns.

\section{REFERÊNCIAS}

BOMENY, Helena. Novos talentos, vícios antigos: os renovadores e a política educacional. Rio de Janeiro, RJ: Estudos Históricos, 1993, vol.6, n11, p.24-39.

BOMENY, Helena. Um poeta na política: Mário de Andrade, paixão e compromisso. Rio de Janeiro, RJ: Casa da Palavra, 2012.

BOURDIEU, Pierre. Razões práticas. Sobre a teoria da ação. Campinas, SP: Papirus, 2007.

CHARTIER, Roger. 0 mundo como representação. Estudos avançados, v. 11, no. 5, p. 173191, 1991.

CHARTIER, Roger. A ordem dos livros. Leitores, autores e bibliotecas na Europa entre os séculosXIV e XVIII. Tradução Mary del Priori. Brasília, DF: Universidade de Brasília, 1999.

CERTEAU, Michel de. A operação histórica. In: Le Goff, Jacques, comp. História: novos problemas, direção de Jacques Le Goff e Pierre Nora; tradução Theo Santiago, Rio de Janeiro, RJ: Francisco Alves, 1988, p. 17-48.

GINZBURG, Carlo. Olhos de madeira: nove reflexões sobre a distância. Tradução Eduardo Brandão. São Paulo, SP: Companhia das Letras, 2001, p.85-103.

GOMES, Angela de Castro. Essa gente do Rio...: modernismo e nacionalismo. Rio de Janeiro, RJ: Fundação Getúlio Vargas, 1999.

MICELI, Sérgio. Intelectuais à brasileira. São Paulo, SP: Companhia das Letras, 2001.

$\begin{array}{llllll}\text { (c) ETD-Educação Temática Digital } & \text { Campinas, SP } & \text { v.19 } & \text { n.3 } & \text { p.864-881 } & \text { jul./set. } 2017\end{array}$ 
SEVCENKO, Nicolau. O Renascimento Modernista de São Paulo na década de 1920. In: BUENO, Eduardo (Org.). Os nascimentos de São Paulo. Rio de Janeiro, RJ: Ediouro, 2004, p.190-205.

SEVCENKO, Nicolau. Orfeu extático na metrópole: São Paulo, sociedade e cultura nos frementes anos 20. São Paulo, SP: Companhia das Letras, 1992.

SIRINELLI, Jean François. Os intelectuais. In: REMOND, René (Org.). Por uma história política. Rio de Janeiro, RJ: FGV, 2003, p.231-239.

\section{FONTES}

ANDRADE, Mário de. Os contos de Belazarte. São Paulo, SP: Círculo do Livro, [s.d.].

ANDRADE, Mário de. Os filhos da Candinha. São Paulo, SP: Martins; Brasília, DF: Instituto nacional do Livro, 1976.

PICCHIA, Menotti del. Dente de ouro. São Paulo: Ediouro, [s.d.] Coleção Prestígio. Biografia, introdução e notas de Afrânio Coutinho.

PICCHIA, Menotti del. Salomé. Rio de Janeiro, RJ: José Olympio, 1989.

ANDRADE, Oswald. Marco Zero I - A Revolução Melancólica. Rio de Janeiro, RJ: Civilização Brasileira, 1978.

ANDRADE, Oswald. Marco Zero II - Chão. Rio de Janeiro, RJ: Civilização Brasileira, 1974.

ANDRADE, Oswald. Os condenados. Rio de Janeiro, RJ: Civilização Brasileira, 1978.

ANDRADE, Oswald. Um homem sem profissão: Memórias e confissões. Sob as Ordens de Mamãe. Rio de Janeiro, RJ: Civilização Brasileira, 1976.

' Revisão: Denise Santos 